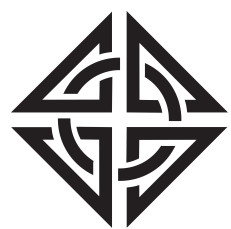

SCIENTIA

I RA N I C A
Sharif University of Technology

Scientia Iranica

Transactions D: Computer Science $\&$ Engineering and Electrical Engineering

www.scientiairanica.com

\title{
Current feedback op-amp based linear voltage-controlled oscillator using analog multipliers and minimum passive components
}

\author{
W. Jaikla ${ }^{a, *}$ and A. Lahiri ${ }^{b}$ \\ a. Department of Engineering Education, Faculty of Industrial Education, King Mongkut's Institute of Technology Ladkrabang, \\ Bangkok, 10520, Thailand. \\ b. D3, Friends Apartment, IP Extension, Delhi, 110092, India.
}

Received 11 October 2014; received in revised form 20 July 2015; accepted 3 November 2015

KEYWORDS
Voltage-controlled
oscillator;
Single-resistance-
controlled oscillator;
Current-feedback
op-amp;
Electronic tuning;
Multiplier.

\section{KEYWORDS}

Voltage-controlled oscillator;

Single-resistancecontrolled oscillator;

Current-feedback

Electronic tuning;

Multiplier.

\begin{abstract}
This paper reports a new realization of linear Voltage-Controlled Oscillator (VCO) using three Current-Feedback Op-Amps (CFOAs), three analog multipliers, and only four passive components. Thus, minimum numbers of passive components are used to devise a canonic sinusoidal oscillator. The circuit provides non-interactive electronic tuning of both the Condition of Oscillation (CO) and the Frequency of Oscillation (FO) via the gains of two different analog multipliers. The impedance at output node exhibits low impedance which is easy to directly connect to load without any additional voltage buffer. The proposed circuit has been simulated in SPICE using macro-model of AD844 CFOA ICs and AD633 multiplier ICs.
\end{abstract}

(C) 2016 Sharif University of Technology. All rights reserved.

\section{Introduction}

Single-Resistance-Controlled Oscillators (SRCOs) have been researched extensively using a variety of active devices in the recent past. Their popularity is mainly attributed to their independent tuning law for the Condition of Oscillation ( $\mathrm{CO}$ ) and the Frequency of Oscillation (FO). In the last decade, the SRCOs, using electronically controllable active devices like the Differential Voltage Current Conveyor Transconductance Amplifier (DVCCTA) [1], the Differential Voltage Current-Controlled Conveyor Transconductance Amplifier (DVCCCTA) [2], Current Controlled Current Differencing Transconductance Amplifiers (CCCDTAs) [3,4], have been proposed. However, these active devices are not commercially available. Among

\footnotetext{
*. Corresponding author. Tel.: +66 23298000 ;

Fax: +6623298435

E-mail addresses: kawinai@kmitl.ac.th (W. Jaikla);

lahiriabhirup@yahoo.com (A. Lahiri)
}

the wide variety of active devices, by which SRCO realizations have been attempted, Current Feedback Op-Amps (CFOAs) remains as one of the most popular choices for the active device. This is because:

(i) CFOAs have many advantages over conventional op-amps, e.g. wide bandwidth independent of the close-loop gain, high slew-rate, and ease of realizing variety of circuit solutions using a reduced number of passive components [5];

(ii) of their commercial availability, e.g. AD844 [6], making them suitable for bread-board implementations;

(iii) Some commercially available CFOAs, like AD844AN with an externally accessible highoutput impedance compensation pin, have been found to be particularly attractive in creating current-mode circuits and particularly ExplicitCurrent-Output (ECO) oscillators [7-11].

Several SRCOs using CFOAs have been reported in the 
literature [5,12-14]. The oscillator circuits in $[5,12,13]$ use two CFOAs and five passive components (three resistors and two capacitors) and the $\mathrm{CO}$ and $\mathrm{FO}$ are controllable via two different resistors. The CFOAbased sinusoidal oscillators in [14] are very excellent circuits. They employ three CFOAs and six passive elements (four resistors and two grounded capacitors). The independent control of both $\mathrm{CO}$ and FO through separate resistors is achieved. Also, the influence of parasitic elements in CFOAs will not affect the CO during the FO tuning process. However, these circuits do not directly offer electronic control of either the $\mathrm{CO}$ or the $\mathrm{FO}$, but the $\mathrm{CO} / \mathrm{FO}$ controlling resistor may be replaced by MOSFET-based Voltage-Controlled Resistor (VCR) [15] to offer electronic control. Recently, a systematic technique of converting SRCO into VCO has been reported by Gupta et al. [16], wherein the frequency controlling resistor (in both grounded and floating forms) has been suitably replaced by FETbased VCR of [17]. The SRCOs, wherein grounded frequency controlling resistor was used, could be transformed into VCOs without requiring any additional CFOAs, but the resulting circuits required matched resistors to realize VCR and FO and were highly temperature dependent (e.g., due to the mobility factor of the employed MOSFET, $\mu$ being proportional to $\left.T^{-1.5}\right)$. An alternate technique to realize $\mathrm{VCO}$ with low temperature dependent FO is to use analog multiplier(s) in the loop so that their multiplier gain terms appear in the $\mathrm{CO}$ and FO. In such a case, $\mathrm{CO}$ and FO will be independently controllable via the voltage gains of two different analog multipliers, which are ratio of two voltages. Several such realizations are available in the literature and their key features are briefed here:

a. The circuit in $[18,19]$ uses three voltage-op amps, a large number of passive components (fourteen or more), and two or more analog multipliers in the feedback loop to realize VCO with independently controllable $\mathrm{CO}$ and $\mathrm{FO}$ by multiplier gains. The dependence of $\mathrm{FO}$ on the control voltage $\left(V_{c}\right)$ for the circuit in [18] is of the form FO being proportional to $\sqrt{V_{c}}$, and for the circuit in [19] is FO being proportional to $V_{c}$, i.e. linear $\mathrm{VCO}$;

b. The circuits in [20] require very few components as compared to the previous circuits $[18,19]$. Employing only one or two voltage op-amps, seven passive components, and two cascaded analog multipliers, the circuits could realize linear VCOs. However, the circuits require matched resistors to realize the Negative Impedance Convertor (NIC) and the CO does not have any electronic control. In addition, the last two oscillator circuits require $\mathrm{CO}$ control by capacitor as compared to the resistor in the first two oscillator circuits;

c. The minimal component count linear VCOs in [21] use only one CFOA, two cascaded analog multipliers, and five passive components. As the circuits in [20], the circuits in [21] lack any electronic control for the $\mathrm{CO}$ and establish the $\mathrm{CO}$ control via capacitors.

In this paper, we propose a new linear VCO with minimum number of passive components (only four) as compared to any of the VCO circuits in [18-21] and with additional feature of independent electronic $\mathrm{CO}$ and FO tuning as compared to the linear VCO circuits in [20,21]. This additional feature is at the cost of increased number of active components, namely three CFOAs and three analog multipliers. However, it should be mentioned that this component count is still much less prevalent than linear VCO with independent electronic CO and FO tuning in [19]. The proposed circuit has been simulated in SPICE using advanced macro-model of AD844 CFOA ICs and AD534 multiplier ICs and the results are in correspondence with the theory.

\section{Proposed circuit}

The proposed VCO circuit is shown in Figure 1. The proposed oscillator consists of three CFOAs, three analog voltage multipliers, two resistors, and two grounded capacitors. Assuming ideal CFOA and multiplier with no parasitic elements and using routine circuit analysis, we get the following characteristic equation:

$$
\begin{aligned}
s^{2} C_{1} C_{2} R_{1} R_{2} & +s A_{2}\left(C_{1} R_{1}+C_{2} R_{2}-A_{1} C_{2} R_{1}\right) \\
& +A_{2}^{2}=0 .
\end{aligned}
$$

Here, $A_{1}$ and $A_{2}$ are the gains of the first and second analog multipliers. From Eq. (1), the condition of oscillation and frequency of oscillation are written as:

$$
\mathrm{CO}: \quad C_{1} R_{1}+C_{2} R_{2} \leq A_{1} C_{2} R_{1},
$$

and:

$$
\text { FO: } \quad f_{0}=\frac{A_{2}}{2 \pi} \sqrt{\frac{1}{C_{1} C_{2} R_{1} R_{2}}} .
$$

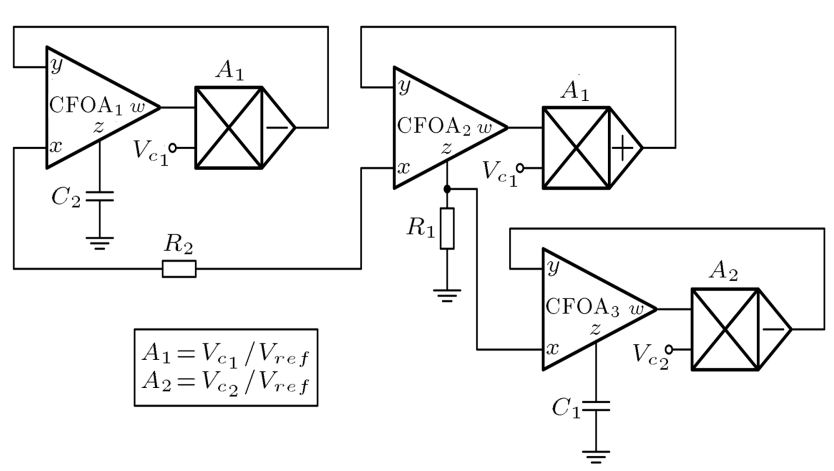

Figure 1. The proposed VCO circuit. 
It is evident from Eqs. (2) and (3) that the CO and FO can be independently controlled via the analog multiplier gains, $A_{1}$ and $A_{2}$, respectively. Also, since FO is proportional to $A_{2}$, the circuit is a linear VCO. Now, considering the non-zero parasitic resistance $R_{x}$ at the $x$ terminal of the CFOA, parasitic resistance $R_{z}$ and parasitic capacitance $C_{z}$ at the high-output impedance $z$ terminal of the CFOA, and external resistors $R_{1}, R_{2}<<R_{z}$ (such a condition in most cases is necessarily required to practically realize an oscillator with pseudo de-coupled CO and FO tuning laws [21]), we find the modified $\mathrm{FO}$ as:

$$
\text { FO: } \quad f_{0}^{\prime}=\frac{A_{2}}{2 \pi} \sqrt{\frac{R_{2}}{\left(C_{1}+C_{z}\right)\left(C_{2}+2 C_{z}\right) R_{1}\left(R_{2}+R_{x}\right)^{2}}}
$$

and:

$$
\mathrm{FO}: \quad f_{0}^{\prime} \approx f_{0}\left[1-\left(\frac{C_{z}}{2 C_{1}}+\frac{C_{z}}{C_{2}}+\frac{R_{x}}{R_{2}}\right)\right] .
$$

\section{Simulation results}

The proposed circuit was simulated in SPICE using advanced macro-model of the commercially available CFOA and analog multiplier ICs. AD844 was used as the CFOA IC and AD633 as the analog multiplier IC. The gain of AD633 analog multiplier is $V_{c} / 10\left(V_{\text {ref }}=\right.$ $10 \mathrm{~V})$ [22]. With voltage supplies of $\pm 16 \mathrm{~V}$, passive component values of $C_{1}=C_{2}=1 n F, R_{1}=1 \mathrm{k} \Omega$, and $R_{2}=5 \mathrm{k} \Omega$, the $\mathrm{CO}$ was set with $A_{1}=1.24\left(V_{c 1}=\right.$ $12.4 \mathrm{~V})$ and FO was set with $A_{2}=1\left(V_{c 2}=10 \mathrm{~V}\right)$. With these values, the ideal FO according to Eq. (3) would be $71.17 \mathrm{kHz}$, according to Eq. (4) should be $69.97 \mathrm{kHz}$ (noting that for $\mathrm{AD} 844, R_{x}=50 \Omega, C_{z}=4.5 \mathrm{pF}$ ) and the observed frequency from simulations was 69.01 $\mathrm{kHz}$. The starting and steady-state waveforms of the signal across the $w$ terminal of the second CFOA and its frequency spectrum (magnitude) are shown in Figure 2(a), (b), and (c), respectively. The Total Harmonic Distortion (THD) is about $1.45 \%$. Practically, the THD value could be decreased by setting $A_{1}$ close to $\left(C_{1} R_{1}+C_{2} R_{2}\right) / C_{2} R_{1}$. Also, the Automatic Gain Control (AGC) circuit can be used instead of $A_{1}$. To investigate the stability of the proposed oscillator, the PSpice Monte-Carlo analysis with 5\% Gaussian deviation on capacitors was used. In this study, 100 samples were run for verifying the oscillation frequency. The result is illustrated in Figure 3. It reveals that the proposed oscillator works well against capacitance tolerance.

\section{Experimental results}

The working of the proposed oscillator was also verified using experimental results. With voltage supplies of

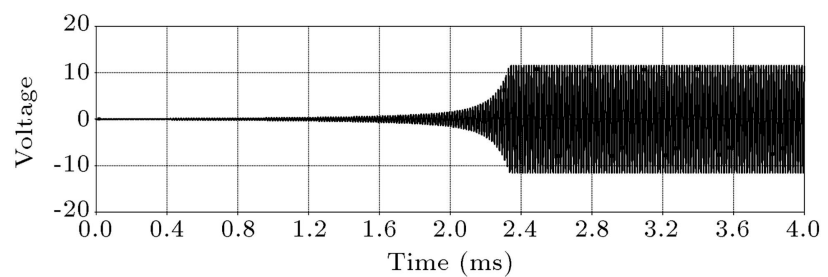

(a)

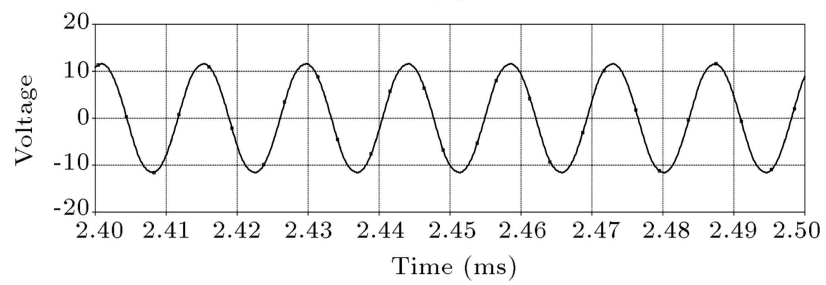

(b)

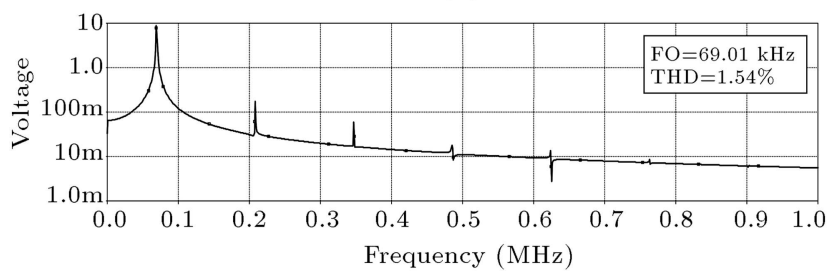

(c)

Figure 2. a) Start-up output voltage. b) Steady-state oscillation waveform. c) Frequency Spectrum.

$\pm 16 \mathrm{~V}$, passive component values of $C_{1}=C_{2}=1 \mathrm{nF}$, $R_{1}=1 \mathrm{k} \Omega$, and $R_{2}=5 \mathrm{k} \Omega$, the CO was set with $A_{1}=$ $1.228\left(V_{c 1}=12.28 \mathrm{~V}\right)$ and FO was set with $A_{2}=1$ $\left(V_{c 2}=10\right)$. With these values, the ideal FO according to Eq. (3) would be $71.17 \mathrm{kHz}$; however, the observed frequency from experiment was $62.92 \mathrm{kHz}$. The steadystate waveforms of the signal across the $w$ terminal of the second CFOA and its frequency spectrum are shown in Figure 4(a) and (b), respectively. The output waveforms and their spectrums for $V_{c 2}=5 \mathrm{~V}, 8 \mathrm{~V}$, $11 \mathrm{~V}$, and $13 \mathrm{~V}$ are respectively illustrated in Figures 5, 6,7 , and 8 . The variation of the $\mathrm{FO}$ with $V_{c 2}$ is shown in Figure 9.

\section{Conclusions}

We have proposed a new linear VCO, which although employs more active components than those of the linear VCO in [21], it provides independent electronic $\mathrm{CO}$ and FO tuning via the gains of the employed analog multipliers. As compared with the linear VCO in [19], which also has independent $\mathrm{CO}$ and FO tuning law, our circuit employs reduced number of active and passive components. In fact, our circuit employs minimum number of passive components as compared to any previous VCO in [18-21]. Simulation results using macro-model of commercially available ICs have proved the workability of the proposed circuit. The realizations of VCO with the same features as those in this circuit, but with reduced number of active 


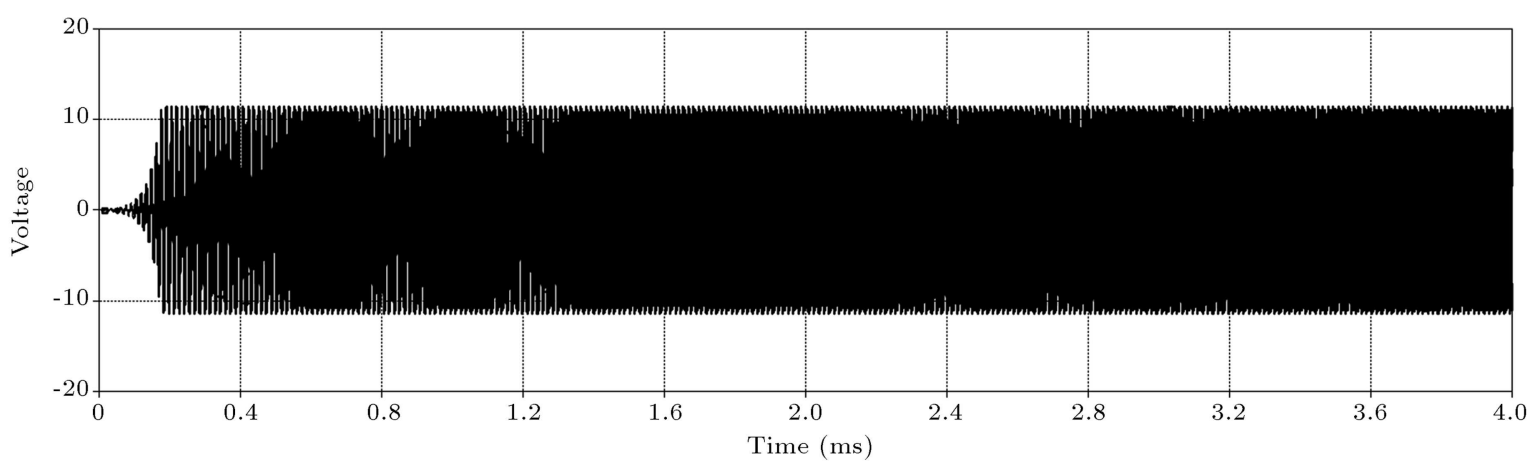

(a)

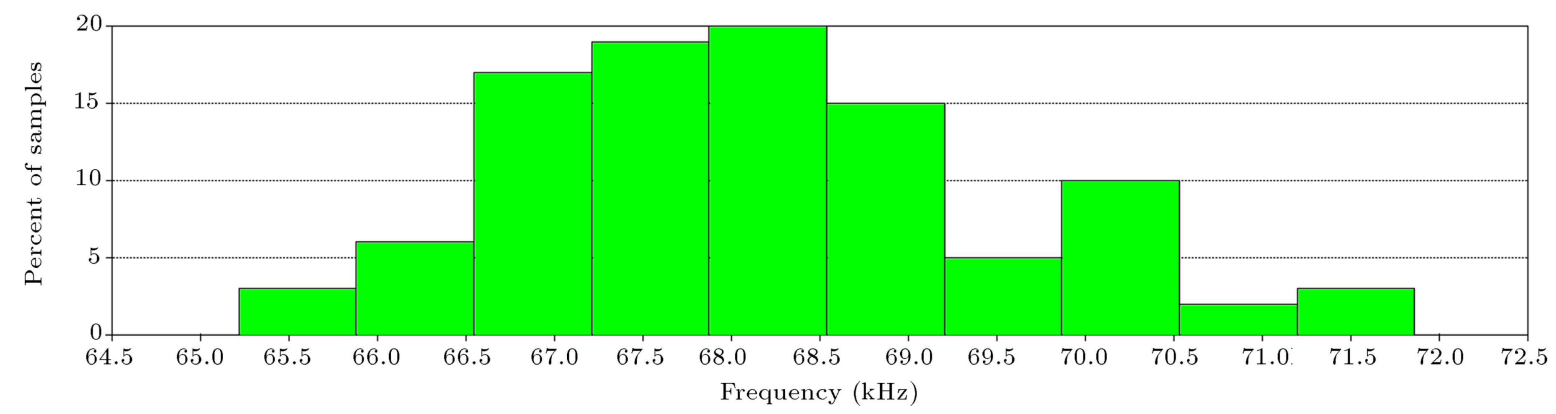

(b)

\begin{tabular}{|lllll|}
\hline$n$ samples $=100$ & Mean $=68158.5$ & Minimum $=65216$ & Median=68077.6 & Maximum=71861.5 \\
$n$ divisions $=10$ & Sigma $=1387.92$ & 10th \%ile=66559 & 90th \%ile=70204.2 & $3 *$ sigma=4163.77 \\
\hline
\end{tabular}

Figure 3. Monte-Carlo simulation of the proposed oscillator at $5 \%$ deviation of capacitance.

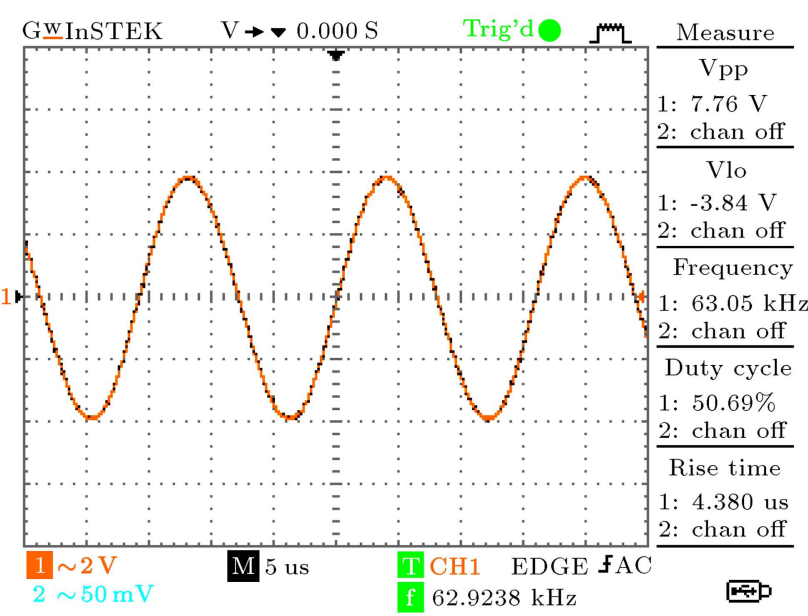

(a)

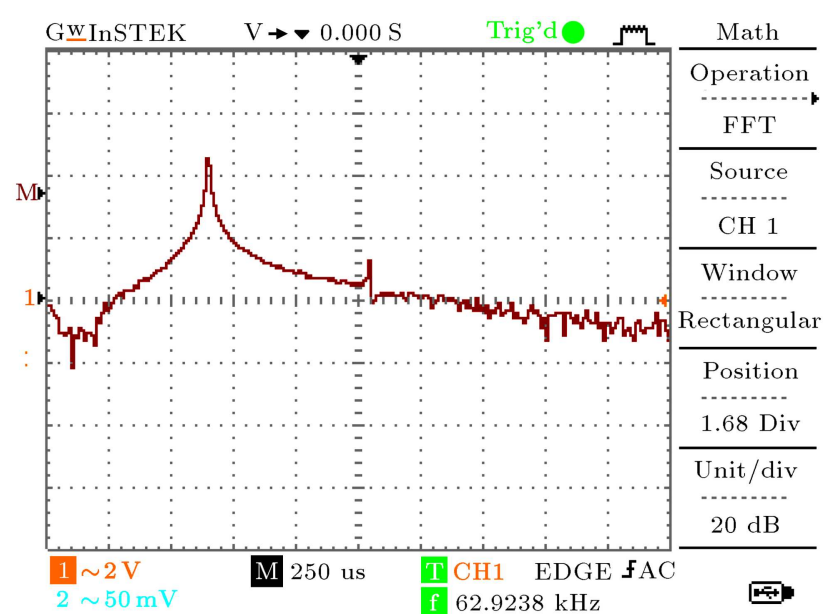

(b)

Figure 4. a) Oscillation waveform. b) Frequency spectrum.

components are a challenging problem which needs to be worked out.

\section{Acknowledgements}

The authors would like to thank the anonymous reviewers for providing valuable comments which helped to improve the paper, substantially. The research described in this paper was financially supported by King Mongkut's Institute of Technology Ladkrabang
(KMITL) and by National Research Council of Thailand (NRCT), Grant No. A118-59-028.

\section{Abbreviations}

SRCO Single-Resistance-Controlled Oscillator;

$\mathrm{CO} \quad$ Condition of Oscillation;

FO Frequency of Oscillation; 


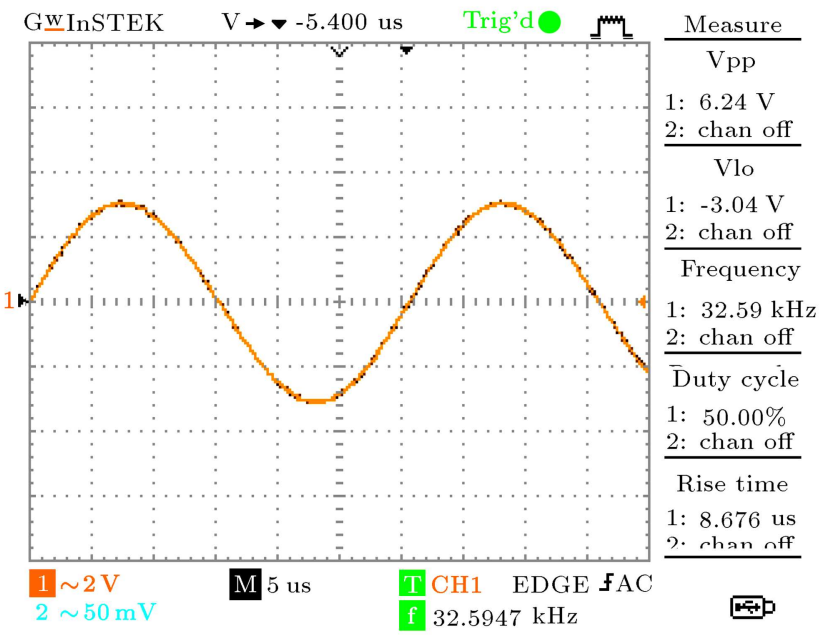

(a)

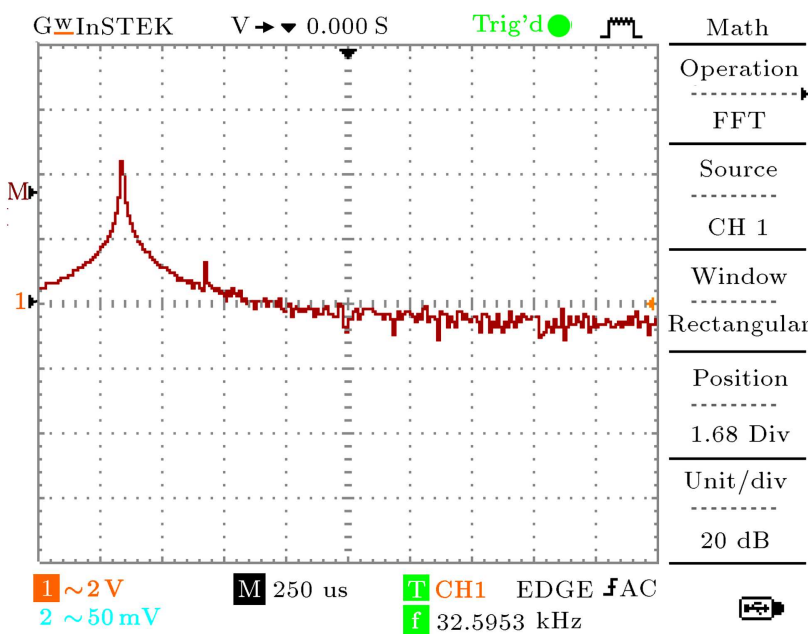

(b)

Figure 5. a) Oscillation waveform. b) Frequency spectrum at $V_{c 2}=5 \mathrm{~V}$.

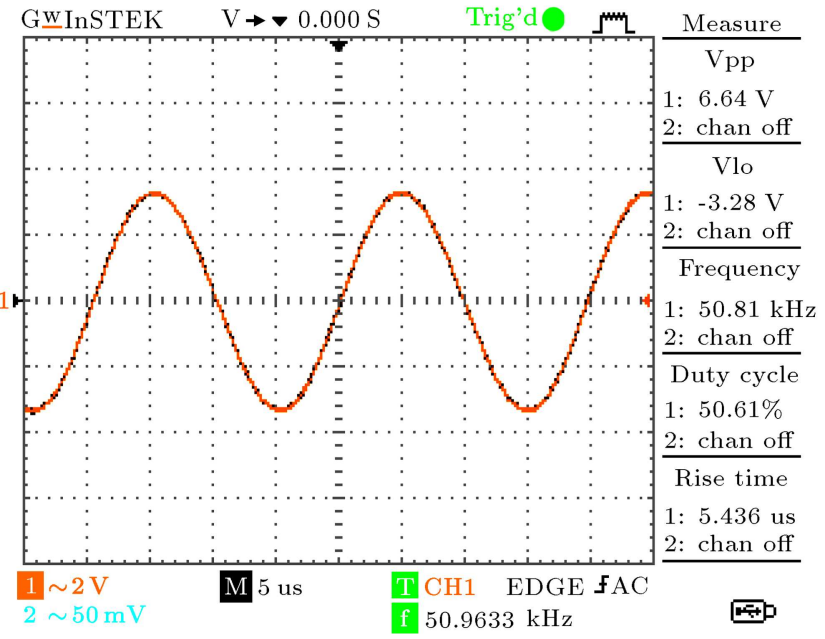

(a)

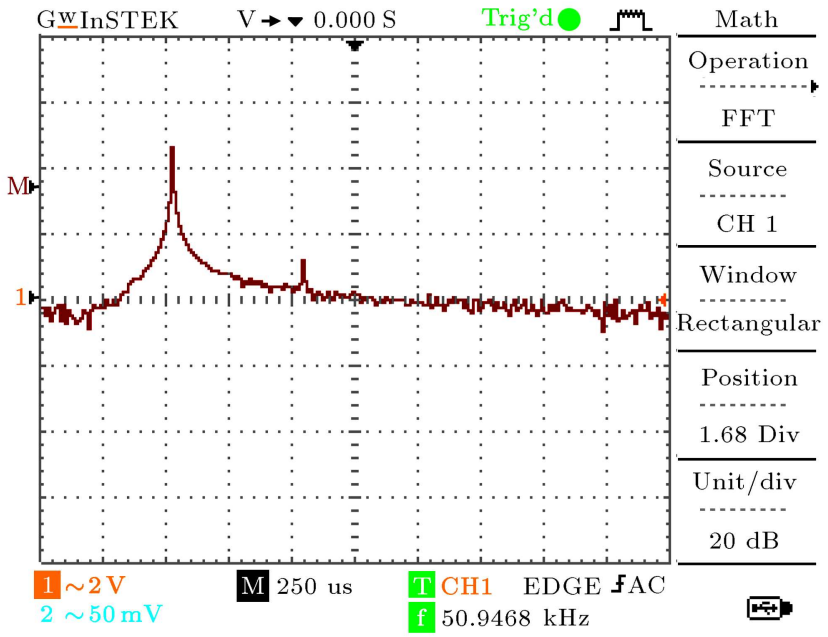

(b)

Figure 6. a) Oscillation waveform. b) Frequency spectrum at $V_{c 2}=8 \mathrm{~V}$.

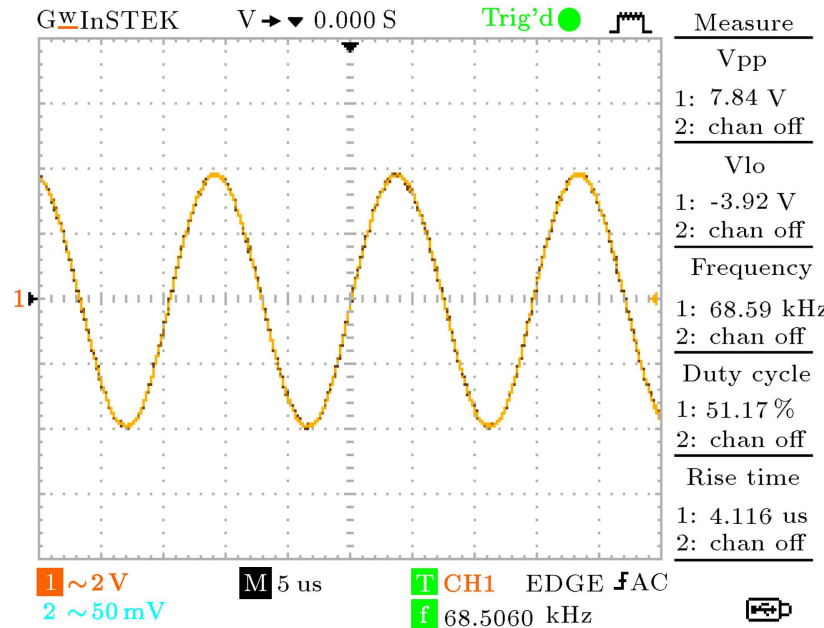

(a)

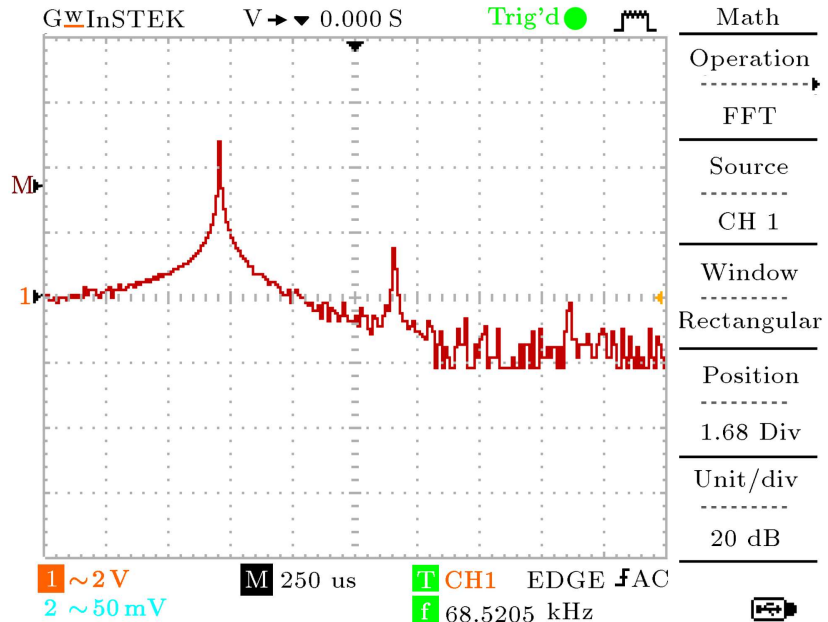

(b)

Figure 7. a) Oscillation waveform. b) Frequency spectrum at $V_{c 2}=11 \mathrm{~V}$. 


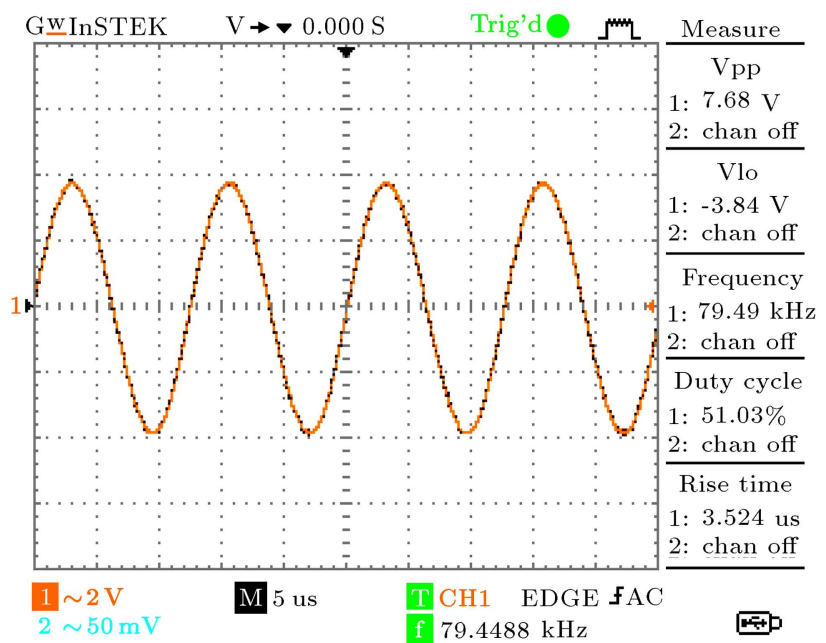

(a)

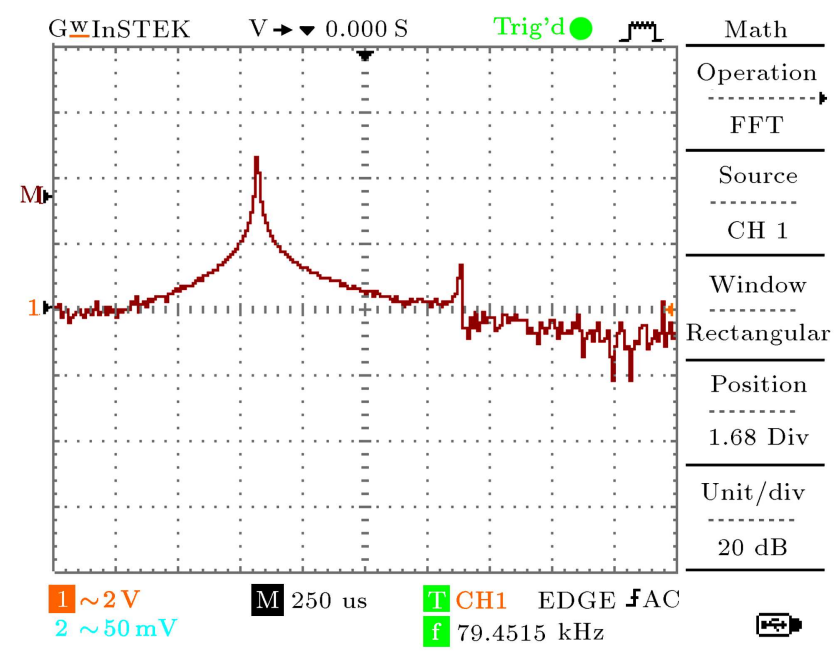

(b)

Figure 8. a) Oscillation waveform. b) Frequency spectrum at $V_{c 2}=13 \mathrm{~V}$.

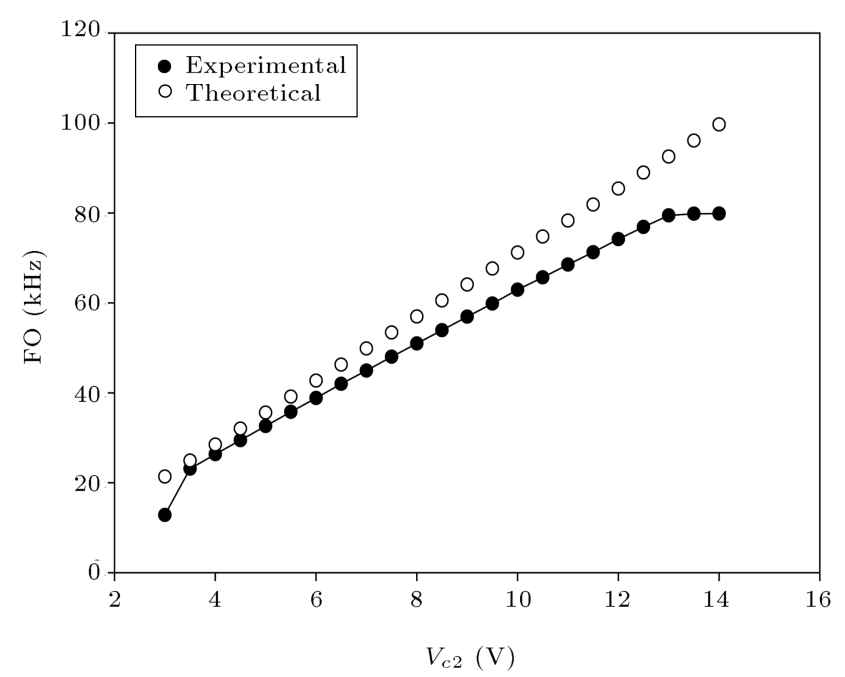

Figure 9. Variations of the frequency of oscillation with control voltage $V_{c 2}$.

\section{CFOAs Current Feedback Op-Amps; \\ VCO Voltage-Controlled Oscillator; \\ VCR Voltage-Controlled Resistor.}

\section{References}

1. Lahiri, A., Jaikla, W. and Siripruchyanun, M. "Voltage-mode quadrature sinusoidal oscillator with current tunable properties", Analog Integrated Circuits and Signal Processing, 65(2), pp. 321-325 (2010).

2. Jaikla, W., Siripruchyanun, M. and Lahiri, A. "Resistorless dual-mode quadrature sinusoidal oscillator using a single active building block", Microelectronics Journal, 42(1), pp. 135-140 (2011).

3. Jaikla, W. and Lahiri, A. "Resistor-less current-mode four-phase quadrature oscillator using CCCDTAs and grounded capacitors", AEU - International Journal of Electronics and Communications, 66, pp. 214-218 (2012).

4. Sakul, C., Jaikla, W. and Dejhan, K. "New resistorless current-mode quadrature oscillators using 2 CCCDTAs and grounded capacitors", Radioengineering, 20(4), pp. 890-897 (2011).

5. Senani, R. and Singh, V.K. "Novel singleresistance-controlled-oscillator configuration using current-feedback-amplifiers", IEEE Transactions on Circuits and Syst. I, 43, pp. 698-700 (1996).

6. Analog Devices, Linear Products Data Book, Norwood, MA (1990).

7. Senani, R. and Sharma, R.K. "Explicit-current-output sinusoidal oscillators employing only a single currentfeedback op-amp", IEICE Electronics Express, 2, pp. 14-18 (2005).

8. Gupta, S.S., Sharma, R.K., Bhaskar, D.R. and Senani, R. "Sinusoidal oscillators with explicit current output employing current-feedback op-amps", International Journal of Circuit Theory and Applications, 3, pp. 131147 (2010).

9. Gupta, S.S., Sharma, R.K., Bhaskar, D.R. and Senani, R. "Synthesis of sinusoidal oscillators with explicit-current-output using current feedback Opamps", WSEAS Transactions on Electronics, 3, pp. $385-388$ (2006).

10. Lahiri, A., Jaikla, W. and Siripruchyanun, M. "Explicit-current-output second-order sinusoidal oscillators using two CFOAs and grounded capacitors", $A E U$ - International Journal of Electronics and Communications, 65, pp. 669-672 (2010).

11. Lahiri, A., Jaikla, W. and Siripruchyanun, M. "First CFOA-based explicit-current-output quadrature sinusoidal oscillators using grounded capacitors", International Journal of Electronics, 100(2), pp. 259-273 (2013).

12. Singh, V.K., Sharama, R.K., Singh, A.K., Bhaskar, D.R. and Senani, R. "Two new canonic single-CFOA oscillators with single resistor controls", IEEE Transactions on Circuits and Systems II, 52, pp. 860-864 (2005). 
13. Gupta, S.S. and Senani, R. "State variable synthesis of single resistance controlled grounded capacitor oscillators using only two CFOAs", IEE Proceedings Circuits, Devices and Systems, 145, pp. 135-138 (1998).

14. Bhaskar, D.R., Gupta, S.S., Senani, R. and Singh, A.K. "New CFOA-based sinusoidal oscillators retaining independent control of oscillation frequency even under the influence of parasitic impedances", Analog Integrated Circuits and Signal Processing, 73, pp. 427437 (2012).

15. Maundy, B., Gift, S. and Aronhime, P. "Practical voltage/current-controlled grounded resistor with dynamic range extension", IET Circuits Devices and Systems, 2(2), pp. 201-206 (2008).

16. Gupta, S.S., Bhaskar, D.R. and Senani, R. "New voltage controlled oscillators using CFOAs", $A E U$ International Journal of Electronics and Communications, 63(9), pp. 209-217 (2009).

17. Nay, K.W. and Budak, A. "A voltage-controlledresistance with wide dynamic range and low distortion", IEEE Transactions on Circuits and Systems, CAS-30, pp. 770-722 (1983).

18. Singh, V.P. and Saha, S.K. "Voltage controlled oscillator with sine-wave output", IEEE Transactions on Instrumentation and Measurement, 37(1), pp. 151-153 (1988).

19. Saha, S.K. and Jain, L.C. "Linear voltage controlled oscillator", IEEE Transactions on Instrumentation and Measurement, 37(1), pp. 148-150 (1988).

20. Bhaskar, D.R. and Tripathi, M.P. "Realization of novel linear sinusoidal VCOs", Analog Integrated Circuits and Signal Processing, 24, pp. 263-267 (2000).

21. Bhaskar, D.R., Senani, R., Singh, A.K. and Gupta, S.S. "Two simple analog multipliers based linear VCOs using a single current feedback op-amp", Circuits and Systems, 1, pp. 1-4 (2010).

22. http://www.analog.com/media/en/technicaldocumentation/data-sheets/AD633.pdf

\section{Biographies}

Winai Jaikla was born in Buriram, Thailand. He received the $\mathrm{BSc}$ degree in Telecommunication Engineering from King Mongkut's Institute of Technology
Ladkrabang (KMITL), Thailand, in 2002, MTech in Electrical Technology, and PhD in Electrical Education from King Mongkut's University of Technology North Bangkok (KMUTNB), Thailand, in 2004 and 2010, respectively. From 2004 to 2011 he was with Electric and Electronic Program, Faculty of Industrial Technology, Suan Sunandha Rajabhat University, Bangkok, Thailand. He has been with the Department of Engineering Education, Faculty of Industrial Education, King Mongkut's Institute of Technology Ladkrabang, Bangkok, Thailand, since 2012.

His research interests include electronic communications, analog signal processing, and analog integrated circuits. He is a member of ECTI, Thailand. He is the author or coauthor of about 50 papers published in scientific journals or conference proceedings. He is an editorial board member of Far East Journal of Electronics and Communications.

Abhirup Lahiri received the BEng degree with the highest honors from the Division of Electronics and Communications, Netaji Subhas Institute of Technology (erstwhile, Delhi Institute of Technology), University of Delhi, India. He has been with STMicroelectronics since 2009, working in different IP groups in the field of analog circuit design. In the past, he was responsible for the development of analog IPs like band-gap references, regulators, crystal oscillators, RC oscillators, LC oscillators, frequency-locked loops, and analog phase-locked loops. His past research works include design of compact analog circuit solutions using novel voltage-mode and current-mode active elements.

His current research interests include low-power and low-voltage analog circuit design and precision voltage and current reference generation. He has authored/co-authored more than 30 international journal/conference papers (including 15 SCI/SCI-E publications) and has acted as a reviewer (by editor's invitation) for numerous international journals and conferences of repute. He served as a program committee member for the 33rd International Conference on Telecommunications and Signal Processing (TSP). $\mathrm{He}$ is an editorial board member of Radioengineering Journal. 